\title{
Computing Improved Fuzzy Optimal Hungarian Assignment Problems with Fuzzy Costs under Robust Ranking Techniques
}

\author{
R.Nagarajan \\ Assistant Professor, \\ Department of Mathematics, \\ J.J College of Engineering \& Technology, \\ Tiruchirappalli- 09. Tamil Nadu, India.
}

\begin{abstract}
Assignment problem (AP) is a well known topic and is used very often in solving problems of engineering and management science. In this problem $a_{i j}$ denotes the cost for assigning the $\mathrm{j}^{\text {th }}$ job to the $\mathrm{i}^{\text {th }}$ person. The cost is usually deterministic in nature. In this paper $\tilde{a}_{i j}$ has been considered to be trapezoidal and triangular numbers denoted by $\tilde{a}_{i j}$ which are more realistic and general in nature. Robust's ranking method [10] has been used for ranking the fuzzy numbers. The fuzzy assignment problem has been transformed into crisp assignment problem in the linear programming problem form and solved by using Hungarian method; Numerical examples show that the fuzzy ranking method offers an effective tool for handling the fuzzy assignment problem.
\end{abstract}

Key words: Fuzzy sets (normal and convex) Triangular fuzzy number, Trapezoidal fuzzy number, Fuzzy assignment problem, fuzzy ranking.

2000AMS Subject Classification: 90C08, 91B24, 91B18

\section{Introduction}

Assignment problem is used worldwide in solving real world problems. An assignment problem plays an important role in industry and other applications. In an

\author{
A.Solairaju \\ Associate Professor, \\ PG \&Research Department of Mathematics, \\ Jamal Mohamed College, \\ Tiruchirappalli- 09. Tamil Nadu, India.
}

assignment problem, $\mathrm{n}$ jobs are to be performed by $\mathrm{n}$ persons depending on their efficiency to do the job. We assume that one person can be assigned exactly one job; also each person can do at most one job. The problem is to find an optimum assignment so that the total cost of performing all jobs is minimum or the total profit is maximum. In this paper, we investigate more realistic problems, namely the assignment problem with fuzzy costs $\tilde{\mathrm{a}}_{\mathrm{ij}}$. Since the objectives are to minimize the total cost or to maximize the total profit, subject to some crisp constraints, the objective function is considered also as a fuzzy number. The method is to rank the fuzzy objective values of the objective function by some ranking method for fuzzy numbers to find the best alternative. On the basis of this idea the Robust's ranking method [10] has been adopted to transform the fuzzy assignment problem to a crisp one so that the conventional solution methods may be applied to solve assignment problem. The idea is to transform a problem with fuzzy parameters to a crisp version in the LPP form and solve it by the simplex method. Other than the fuzzy assignment problem other applications of this method can be tried in project scheduling, maximal flow, transportation problem etc.

Lin and wen solved the AP with fuzzy interval number costs by a labeling algorithm [2]. In the paper by Sakawa 
et.al. [6] , the authors dealt with actual problems on production and work force assignment in a housing material manufacturer and a sub contract firm and formulated two kinds of two level programming problems. Chen [7] proved some theorems and proposed a fuzzy assignment model that considers all individuals to have same skills.. Wang [15] solved a similar modal by graph theory. Dubois and Fortemps [3] surveys refinements of the ordering of solutions supplied by the max-min formulation, namely the discrimin partial ordering and the leximin complete preordering. Different kinds of transportation problems are solved in the articles $[5,8,11,12,13]$.Dominance of fuzzy numbers can be explained by many ranking methods [1,4,9,19,14]. Of these, Robust's ranking method [10] which satisfies the properties of compensation, linearity and additivity. In this paper we have applied Robust's ranking technique [10] .

\section{Preliminaries}

Zadeh [16] in 1965 first introduced Fuzzy set as a mathematical way of representing impreciseness or vagueness in everyday life.

2.1 Definition: A fuzzy set is characterized by a membership function mapping elements of a domain, space, or universe of discourse $X$ to the unit interval $[0,1]$. $(\mathrm{i}, \mathrm{e}) \mathrm{A}=\left\{\left(\mathrm{x}, \mu_{\mathrm{A}}(\mathrm{x}) ; \mathrm{x} \in \mathrm{X}\right\}\right.$, Here $\mu_{\mathrm{A}}: \mathrm{X} \rightarrow[0,1]$ is a mapping called the degree of membership function of the fuzzy set $A$ and $\mu_{A}(x)$ is called the membership value of $x$ $\varepsilon \mathrm{X}$ in the fuzzy set $\mathrm{A}$. These membership grades are often represented by real numbers ranging from $[0,1]$.

2.2 Definition : A fuzzy set A of the universe of discourse $\mathrm{X}$ is called a normal fuzzy set implying that there exist at least one $\mathrm{x} \varepsilon \mathrm{X}$ such that $\mu_{\mathrm{A}}(\mathrm{x})=1$.
2.3 Definition ; The fuzzy set A is convex if and only if, for any $x_{1}, x_{2} \in X$, the membership function of $A$ satisfies the inequality $\mu_{\mathrm{A}}\left\{\lambda \mathrm{x}_{1}+(1-\lambda) \mathrm{x}_{2}\right\} \geq \min \left\{\mu_{\mathrm{A}}\left(\mathrm{x}_{1}\right), \mu_{\mathrm{A}}\left(\mathrm{x}_{2}\right)\right\} .0 \leq$ $\lambda \leq 1$.

2.4 Definition (Triangular fuzzy number) : For a triangular fuzzy number $\mathrm{A}(\mathrm{x})$, it can be represented by $\mathrm{A}(\mathrm{a}, \mathrm{b}, \mathrm{c} ; 1)$ with membership function $\mu(\mathrm{x})$ given by

$\mu(x)=\left\{\begin{array}{cl}(x-a) /(b-a), & a \leq x \leq b \\ 1, & x=b \\ (c-x) /(c-b), & c \leq x \leq d \\ 0, & \text { otherwise }\end{array}\right.$

2.5 Definition: (Trapezoidal fuzzy number): For a trapezoidal number $\mathrm{A}(\mathrm{x})$, it can be represented by $\mathrm{A}(\mathrm{a}, \mathrm{b}, \mathrm{c}, \mathrm{d} ; 1)$ with membership function $\mu(\mathrm{x})$ given by

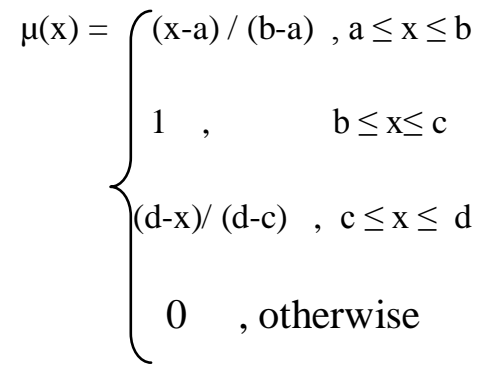

2.6 Definition: ( $\alpha$-cut of a trapezoidal fuzzy number): The $\alpha$-cut of a fuzzy number $\mathrm{A}(\mathrm{x})$ is defined as $\mathrm{A}(\alpha)=\{\mathrm{x}$ : $\mu(\mathrm{x}) \geq \alpha, \alpha \in[0,1]\}$

Addition of two fuzzy numbers can be performed as $\left(a_{1}, b_{1}, c_{1}\right)+\left(a_{2}, b_{2}, c_{2}\right)=\left(a_{1}+a_{2}, b_{1}+b_{2}, c_{1}+c_{2}\right)$

Addition of two trapezoidal fuzzy numbers can be performed as

$\left(a_{1}, b_{1}, c_{1}, d_{1}\right)+\left(a_{2}, b_{2}, c_{2}, d_{2}\right)=\left(a_{1}+a_{2}, b_{1}+b_{2}, c_{1}+c_{2}, d_{1}+d_{2}\right)$. 


\section{Robust's Ranking Techniques - Algorithms}

The Assignment Problem can be stated in the form of $n \times n$ cost matrix $\left[\mathrm{a}_{\mathrm{ij}}\right]$ of real numbers as given in the following

\begin{tabular}{|l|l|l|l|l|l|}
\hline & Job1 & Job2 & Job3 &. Jobj & JobN \\
\hline Person 1 & $\mathrm{a}_{11}$ & $\mathrm{a}_{12}$ & $\mathrm{a}_{13}$ &.. $\mathrm{a}_{1 \mathrm{j} \cdot \cdot}$ & $\mathrm{a}_{1 \mathrm{n}}$ \\
\hline Person 2 & $\mathrm{a}_{21}$ & $\mathrm{a}_{22}$ & $\mathrm{a}_{23}$ &.. $\mathrm{a}_{2 \mathrm{j}}$ & $\mathrm{a}_{2 \mathrm{n}}$ \\
\hline$\cdot$ & - & - & - & - & - \\
\hline Person $\mathrm{i}$ & $\mathrm{a}_{\mathrm{i} 1}$ & $\mathrm{a}_{\mathrm{i} 2}$ & $\mathrm{a}_{\mathrm{i} 3}$ &.. $\mathrm{a}_{\mathrm{ij} \cdot} \cdot$ & $\mathrm{a}_{\mathrm{in}}$ \\
\hline$\cdot$ & - & - & - & - & - \\
\hline PersonN & $\mathrm{a}_{\mathrm{n} 1}$ & $\mathrm{a}_{\mathrm{n} 2}$ & $\mathrm{a}_{\mathrm{n} 3}$ &.. $\mathrm{a}_{\mathrm{nj} \cdot \cdot}$ & $\mathrm{a}_{\mathrm{nn}}$ \\
\hline
\end{tabular}

Mathematically assignment problem can be stated as

Minimize $\mathrm{z}=\sum_{i=1}^{n} \sum_{j=1}^{n}$ aij xij

Subject to

$$
\begin{aligned}
& \sum_{i=1}^{n} x_{i j}=1 \\
& \sum_{j=1}^{n} x_{i j}=1 \quad \text { x }_{\mathrm{ij}} \in[0,1]
\end{aligned}
$$

where $\mathrm{x}_{\mathrm{ij}}=\left\{\begin{array}{l}1, \text { if the } \mathrm{i}^{\text {th }} \text { person is assigned the } \mathrm{j}^{\text {th }} \text { job } \\ 0, \text { otherwise }\end{array}\right.$

is the decision variable denoting the assignment of the person $\mathrm{i}$ to job $\mathrm{j}$. $\tilde{\mathrm{a}}_{\mathrm{ij}}$ is the cost of assigning the $\mathrm{j}^{\text {th }}$ jog to the $i^{\text {th }}$ person. The objective is to minimize the total cost of assigning all the jobs to the available persons. (one job to one person).
When the costs or time ãij are fuzzy numbers, then the total cost becomes a fuzzy number.

$\check{\mathrm{z}}=\sum_{i=1}^{n} \sum_{j=1}^{n}$ aij $\mathrm{xij}$. Hence it cannot be minimized directly. For solving the problem we defuzzify the fuzzy cost coeffients into crisp ones by a fuzzy number ranking method.

Robust's ranking technique [10] which satisfies compensation, linearity, and additivity properties and provides results which are consistent with human intuition. Give a convex fuzzy number ã , the Robust's Ranking Index is defined by

$$
\mathrm{R}(\tilde{\mathrm{a}})=\int_{0}^{1} 0.5\left(\mathrm{a}_{\alpha}{ }^{\mathrm{L}}, \mathrm{a}_{\alpha}{ }^{\mathrm{U}}\right) \mathrm{d} \alpha, \text { where }\left(\mathrm{a}_{\alpha}{ }^{\mathrm{L}}, \mathrm{a}_{\alpha}{ }^{\mathrm{U}}\right) \text { is the } \alpha-
$$

level cut of the fuzzy number ã.

In this paper we use this method for ranking the objective values. The Robust's ranking index $\mathrm{R}(\tilde{\mathrm{a}})$ gives the representative value of the fuzzy number ã . It satisfies the linearity and additive property:

If $\hat{\mathrm{G}}=\ell_{\hat{\mathrm{E}}}+\mathrm{m}_{\tilde{\mathrm{Y}}}$ and $\tilde{\mathrm{U}^{\prime}}=\mathrm{k}_{\hat{\mathrm{A}}}-\mathrm{t}_{\tilde{\mathrm{N}}}$, where $\ell, \mathrm{m}, \mathrm{k}$ and $\mathrm{t}$ are constants, then we have

$\mathrm{R}(\hat{\mathrm{G}})=\ell \mathrm{R}(\hat{\mathrm{E}})+\mathrm{mR}(\tilde{\mathrm{Y}})$ and $\mathrm{R}\left(\tilde{U}^{\prime}\right)=\mathrm{k} \mathrm{R}(\hat{\mathrm{A}})-\mathrm{t} \mathrm{R}(\tilde{\mathrm{N}})$. On the basis of this property the fuzzy assignment problem can be transformed into a crisp assignment problem in Linear Programming Problem form. The ranking Technique of the Robust is

If $\mathrm{R}(\hat{\mathrm{S}}) \leq \mathrm{R}(\breve{\mathrm{I}})$, then $\hat{\mathrm{S}} \leq \breve{\mathrm{I}}$ i,e $\min \{\hat{\mathrm{S}}, \breve{\mathrm{I}}\}=\hat{\mathrm{S}}$

For the assignment problem (1), with fuzzy objective function Min $\check{z}=\sum_{i=1}^{n} \sum_{j=1}^{n} \mathrm{R}(\tilde{a} \mathrm{ij}) \mathrm{xij}$ 
we apply Robust's ranking method [10] (using the linearity and assistive property) to get the minimum objective value $\check{\mathrm{z}}^{*}$ from the formulation

$\mathrm{R}\left(\check{\mathrm{z}}^{*}\right)=\min \mathrm{z}=\sum_{i=1}^{n} \sum_{j=1}^{n} \mathrm{R}(\tilde{\mathrm{a}} \mathrm{ij}) \mathrm{xij}$

Subject to

$$
\begin{aligned}
& \sum_{i=1}^{n} x_{i j}=1 \\
& \sum_{j=1}^{n} x_{i j}=1, \mathrm{x}_{\mathrm{ij}} \mathrm{E}[0,1]
\end{aligned}
$$

Where $x_{i j}=\left\{\right.$, if the $i^{\text {th }}$ person is assigned to $j^{\text {th }}$ job $\{0$ otherwise.

is the decision variable denoting the assignment of the person $\mathrm{i}$ to $\mathrm{j}$. $\tilde{\mathrm{a}}_{\mathrm{ij}}$ is the cost of designing the $\mathrm{j}^{\mathrm{th}}$ job to the $\mathrm{i}^{\text {th }}$ person. The objective is to minimize the total cost of assigning all the jobs to the available persons.

Since $R\left(\tilde{\mathrm{a}}_{\mathrm{ij}}\right)$ are crisp values, this problem (2) is obviously the crisp assignment problem of the form (1) which can be solved by the conventional methods, namely the Hungarian Method or Simplex method to solve the Linear Programming problem form of the problem. Once the optimal solution $\mathrm{x}^{*}$ of model (2) is found, the optimal fuzzy objective value $\check{z}^{*}$ of the original problem can be calculated as $\check{z}^{*}=\sum_{i=1}^{n} \sum_{j=1}^{n}$ ãij xij *

\section{Numerical Example}

Example-1 : Let us consider a Fuzzy Assignment Problem with rows representing 4 persons A,B,C,D, and columns representing the 4 jobs Job1, Job2, Job3 and Job4, .The cost matrix $\left[\tilde{\mathrm{a}}_{\mathrm{ij}}\right]$ is given whose elements are Triangular fuzzy numbers. The problem is to find the optimal assignment so that the total cost of job assignment becomes minimum

$$
\left[\tilde{\mathrm{a}}_{\mathrm{ij}}\right]=\left(\begin{array}{llll}
(5,10,15) & (5,10,20) & (5,15,20) & (5,10,15) \\
(5,10.20) & (5,15,20) & (5,10,15) & (10,15,20) \\
(5,10.20) & (10,15,20) & (10,15,20) & (5,10,15) \\
(10,15,25) & (5,10,15) & (10,20,30) & (10,15,25)
\end{array}\right)
$$

Solution: In Conformation to model (2) the fuzzy assignment problem can be formulated in the following mathematical programming form

$$
\begin{aligned}
& \operatorname{Min}\left\{\mathrm{R}(5,10,15) \mathrm{x}_{11}+\mathrm{R}(5,10,20) \mathrm{x}_{12}+\mathrm{R}(5,15,20) \mathrm{X}_{13}+\right. \\
& \mathrm{R}(5,10,15) \mathrm{x}_{14}+\mathrm{R}(5,10,20) \mathrm{x}_{21} \\
& +\mathrm{R}(5,15,20) \mathrm{x}_{22}+\mathrm{R}(5,10,15) \mathrm{x}_{23}+\mathrm{R}(10,15,20) \mathrm{x}_{24}+\mathrm{R}(5,10.20) \\
& \mathrm{x}_{31}+\mathrm{R}(10,15,20) \mathrm{x}_{32}+\mathrm{R}(10,15,20) \mathrm{x}_{33}+\mathrm{R}(5,10,15) \mathrm{x}_{34}+\mathrm{R}(10,1 \\
& \left.5,25) \mathrm{x}_{41}+\mathrm{R}(5,10,15) \mathrm{x}_{42}+\mathrm{R}(10,20,30) \mathrm{x}_{43}+\mathrm{R}(10,15,25) \mathrm{x}_{44}\right\}
\end{aligned}
$$

Subject to

$$
\begin{array}{ll}
\mathrm{x}_{11}+\mathrm{x}_{12}+\mathrm{x}_{13}+\mathrm{x}_{14}=1 & \mathrm{x}_{11}+\mathrm{x}_{21}+\mathrm{x}_{31}+\mathrm{x}_{41}=1 \\
\mathrm{x}_{21}+\mathrm{x}_{22}+\mathrm{x}_{23}+\mathrm{x}_{24}=1 & \mathrm{x}_{12}+\mathrm{x}_{22}+\mathrm{x}_{32}+\mathrm{x}_{42}=1 \\
\mathrm{x}_{31}+\mathrm{x}_{32}+\mathrm{x}_{33}+\mathrm{x}_{34}=1 & \mathrm{x}_{13}+\mathrm{x}_{23}+\mathrm{x}_{33}+\mathrm{x}_{43}=1 \\
\mathrm{x}_{41}+\mathrm{x}_{42}+\mathrm{x}_{43}+\mathrm{x}_{44}=1 & \mathrm{x}_{14}+\mathrm{x}_{24}+\mathrm{x}_{34}+\mathrm{x}_{44}=1 \\
\mathrm{x}_{\mathrm{ij}} \mathrm{C}[0,1] &
\end{array}
$$

Now we calculate $\mathrm{R}(5,10,15)$ by applying Robust's ranking method. The membership function of the triangular fuzzy number $(5,10,15)$ is

$$
\mu(x)=\left\{\begin{array}{cc}
(x-5) / 5, & 5 \leq x \leq 10 \\
1, & x=10 \\
(15-x) / 5, & 10 \leq x \leq 15 \\
0, \text { otherwise } &
\end{array}\right.
$$


The $\alpha$-cut of the fuzzy number $(5,10,15)$ is

$\left(a_{\alpha}{ }^{\mathrm{L}}, \mathrm{a}_{\alpha}{ }^{\mathrm{U}}\right)=(5 \alpha+5,15-5 \alpha)$ for which

$$
\begin{aligned}
\mathrm{R}\left(\tilde{\mathrm{a}}_{\mathrm{ij}}\right)=\mathrm{R}(5,10,15) & =\int_{0}^{1} 0.5\left(\mathrm{a}_{\alpha}{ }^{\mathrm{L}}, \mathrm{a}_{\alpha}{ }^{\mathrm{U}}\right) \mathrm{d} \alpha \\
& =\int_{0}^{1} 0.5(20) \mathrm{d} \alpha=10 .
\end{aligned}
$$

Proceeding similarly, the Robust's ranking indices for the fuzzy costs $\tilde{\mathrm{a}}_{\mathrm{ij}}$ are calculated as:

$\mathrm{R}\left(\mathrm{a}_{12}\right)=11.25, \mathrm{R}\left(\mathrm{a}_{13}\right)=13.75, \mathrm{R}\left(\mathrm{a}_{14}\right)=10, \mathrm{R}\left(\mathrm{a}_{21}\right)=15$, $\mathrm{R}\left(\mathrm{a}_{22}\right)=13.75, \mathrm{R}\left(\mathrm{a}_{23}\right)=10, \quad \mathrm{R}\left(\mathrm{a}_{24}\right)=15, \mathrm{R}\left(\mathrm{a}_{31}\right)=11.25$, $\mathrm{R}\left(\mathrm{a}_{32}\right)=15, \quad \mathrm{R}\left(\mathrm{a}_{33}\right)=15, \mathrm{R}\left(\mathrm{a}_{34}\right)=10, \mathrm{R}\left(\mathrm{a}_{41}\right)=16.25$, $\mathrm{R}\left(\mathrm{a}_{42}\right)=10, \mathrm{R}\left(\mathrm{a}_{43}\right)=20, \mathrm{R}\left(\mathrm{a}_{44}\right)=17.5$. we replace these values for their corresponding $\tilde{a}_{\mathrm{ij}}$ in (3) which results in a convenient assignment problem in the Linear programming problem. We solve it by Hungarian method to get the following optimal solution

$\mathrm{x}^{*}{ }_{11}=\mathrm{x}^{*}{ }_{23}=\mathrm{x}^{*}{ }_{34}=\mathrm{x}^{*}{ }_{42}=1$

$\mathrm{X} *{ }_{12}=\mathrm{x}{ }_{13}=\mathrm{x} *{ }_{14}=\mathrm{x}{ }_{21}=\mathrm{x} *{ }_{22}=\mathrm{x} *{ }_{24}=\mathrm{x} *{ }_{31}=\mathrm{x} *{ }_{32}=\mathrm{x} *{ }_{33}=\mathrm{x} *{ }_{41}=\mathrm{x} *{ }_{4}$ ${ }_{3}=\mathrm{X}_{44}=0$ with the optimal objective value $\mathrm{R}\left(\check{\mathrm{Z}}^{*}\right)=40$ which represents the optimum total cost in other words the optimal assignment is $\mathrm{A} \rightarrow 1, \mathrm{~B} \rightarrow 3, \mathrm{C} \rightarrow 4, \mathrm{D} \rightarrow 2 \mathrm{R}\left(\check{\mathrm{Z}}^{*}\right)=40$

The fuzzy optimal total cost $=\tilde{\mathrm{a}}_{11}+\tilde{\mathrm{a}}_{23}+\tilde{\mathrm{a}}_{34}+\tilde{\mathrm{a}}_{42}=$ $\mathrm{R}(5,10,15)+\mathrm{R}(5,10,15)+\mathrm{R}(5,10,15)+\mathrm{R}(5,10,15)=$ $\mathrm{R}(20,40,60)$

Also we find that $\mathrm{R}\left(\check{\mathrm{Z}}^{*}\right)=40$.

Example -2 Let us consider a Fuzzy Assignment Problem with rows representing 5 persons A,B,C,D,E and columns representing the 5jobs Job1, Job2, Job3, Job4,Job5. The cost matrix [ãij] is given whose elements are Trapezoidal fuzzy numbers. The problem is to find the optimal assignment so that the total cost of job assignment becomes minimum.

$\left[\tilde{\mathrm{a}}_{\mathrm{ij}}\right]=\left(\begin{array}{llllll}(4,6,7,9) & (3,5,7,10) & (5,7,10,12) & (3,4,6,9) & (4,5,7,10) \\ (2,3,5,9) & (5,7,9,13) & (4,6,9,12) & (5,6,7,10) & (2,3,5,7) \\ (7,9,10,12) & (6,7,9,10) & (7,9,10,13) & (6,7,10,13) & (7,10,13,14) \\ (4,5,7,9) & (5,7,12,15) & (7,9,13,15) & (2,4,10,13) & (5,7,10,14) \\ (4,10,13,15) & (3,7,9,13) & (2,3,10,14) & (3,7,10,13) & (4,7,10,14)\end{array}\right)$ Solution: In Conformation to model (2) the fuzzy assignment problem can be formulated in the following mathematical programming form

$\operatorname{Min}\left\{\mathrm{R}(4,6,7,9) \mathrm{x}_{11}+\mathrm{R}(3,5,7,10) \mathrm{x}_{12}+\mathrm{R}(5,7,10,12) \mathrm{x}_{13}+\mathrm{R}(3,4\right.$, $6,9) \mathrm{x}_{14}+\mathrm{R}(4,5,7,10) \mathrm{x}_{15}+\mathrm{R}(2,3,5,9) \mathrm{x}_{21}+\mathrm{R}(5,7,9,13) \mathrm{x}_{22}+\mathrm{R}(4$, $6,9,12) \mathrm{x}_{23}+\mathrm{R}(5,6,7,10) \mathrm{x}_{24}+\mathrm{R}(2,3,5,7) \mathrm{x}_{25}+\mathrm{R}(7,9,10,12) \mathrm{x}_{31}+$ $\mathrm{R}(6,7,9,10) \mathrm{x}_{32}+\mathrm{R}(7,9,10,13) \mathrm{X}_{33}+\mathrm{R}(6,7,10,13) \mathrm{x}_{34}+\mathrm{R}(7,10,1$ $3,14) \mathrm{x}_{35}+\mathrm{R}(4,5,7,9) \mathrm{x}_{41}+\mathrm{R}(5,7,12,15) \mathrm{x}_{42}+\mathrm{R}(7,9,13,15) \mathrm{x}_{43}+$ $\mathrm{R}(2,4,10,13) \mathrm{x}_{44}+\mathrm{R}(5,7,10,14) \mathrm{x}_{45}+\mathrm{R}(4,10,13,15) \mathrm{x}_{51}+$ $\mathrm{R}(3,7,9,13) \mathrm{x}_{52}+\mathrm{R}(2,3,10,14) \mathrm{x}_{53}+\mathrm{R}(3,7,10,13) \mathrm{x}_{54}+$ $\left.\mathrm{R}(4,7,10,14) \mathrm{x}_{55}\right\}$

Subject to $\begin{array}{ll}\mathrm{x}_{11}+\mathrm{x}_{12}+\mathrm{x}_{13}+\mathrm{x}_{14}=1 & \mathrm{x}_{11}+\mathrm{x}_{21}+\mathrm{x}_{31}+\mathrm{x}_{41}=1 \\ \mathrm{x}_{21}+\mathrm{x}_{22}+\mathrm{x}_{23}+\mathrm{x}_{24}=1 & \mathrm{x}_{12}+\mathrm{x}_{22}+\mathrm{x}_{32}+\mathrm{x}_{42}=1 \\ \mathrm{x}_{31}+\mathrm{x}_{32}+\mathrm{x}_{33}+\mathrm{x}_{34}=1 & \mathrm{x}_{13}+\mathrm{x}_{23}+\mathrm{x}_{33}+\mathrm{x}_{43}=1 \\ \mathrm{x}_{41}+\mathrm{x}_{42}+\mathrm{x}_{43}+\mathrm{x}_{44}=1 & \mathrm{x}_{14}+\mathrm{x}_{24}+\mathrm{x}_{34}+\mathrm{x}_{44}=1 \quad \mathrm{x}_{\mathrm{ij}} \in[0,1]\end{array}$

Now we calculate $R(4,6,7,9)$ by applying Robust's ranking method. The membership function of the Trapezoidal fuzzy number $(4,6,7,9)$ is 


$$
\mu(x)=\left\{\begin{array}{l}
(x-4) / 2,4 \leq x \leq 6 \\
1,6 \leq x \leq 7 \\
(9-x) / 2, \quad 7 \leq x \leq 9 \\
0, \text { otherwise }
\end{array}\right.
$$

The $\alpha$-cut of the fuzzy number $(4,6,7,9)$ is

$\left(a_{\alpha}{ }^{\mathrm{L}}, \mathrm{a}_{\alpha}{ }^{\mathrm{U}}\right)=(2 \alpha+4,9-2 \alpha)$ for which

$$
\begin{aligned}
\mathrm{R}\left(\tilde{\mathrm{a}}_{\mathrm{ij}}\right)=\mathrm{R}(4,6,7,9) & =\int_{0}^{1} 0.5\left(\mathrm{a}_{\alpha}^{\mathrm{L}}, \mathrm{a}_{\alpha}{ }^{\mathrm{U}}\right) \mathrm{d} \alpha \\
& =\int_{0}^{1} 0.5(13) \mathrm{d} \alpha=6.5 .
\end{aligned}
$$

Proceeding similarly, the Robust's ranking indices for the fuzzy costs $\tilde{\mathrm{a}}_{\mathrm{ij}}$ are calculated as:

$\mathrm{R}\left(\mathrm{a}_{12}\right)=6.25, \mathrm{R}\left(\mathrm{a}_{13}\right)=8.5, \mathrm{R}\left(\mathrm{a}_{14}\right)=5.5, \mathrm{R}\left(\mathrm{a}_{15}\right)=6.5$, $\mathrm{R}\left(\mathrm{a}_{21}\right)=4.75, \mathrm{R}\left(\mathrm{a}_{22}\right)=8.5, \mathrm{R}\left(\mathrm{a}_{23}\right)=15.5, \mathrm{R}\left(\mathrm{a}_{24}\right)=7, \mathrm{R}\left(\mathrm{a}_{25}\right)$ $=4.25, \mathrm{R}\left(\mathrm{a}_{31}\right)=9.5, \mathrm{R}\left(\mathrm{a}_{32}\right)=8, \mathrm{R}\left(\mathrm{a}_{33}\right)=9.75, \mathrm{R}\left(\mathrm{a}_{34}\right)=9$, $\mathrm{R}\left(\mathrm{a}_{35}\right)=11, \mathrm{R}\left(\mathrm{a}_{41}\right)=6.25, \mathrm{R}\left(\mathrm{a}_{42}\right)=9.75, \mathrm{R}\left(\mathrm{a}_{43}\right)=11, \mathrm{R}\left(\mathrm{a}_{44}\right)$ $=7.25, \mathrm{R}\left(\mathrm{a}_{45}\right)=9, \mathrm{R}\left(\mathrm{a}_{51}\right)=10.5, \mathrm{R}\left(\mathrm{a}_{52}\right)=8, \mathrm{R}\left(\mathrm{a}_{53}\right)=7.25$, $\mathrm{R}\left(\mathrm{a}_{54}\right)=7.75, \mathrm{R}\left(\mathrm{a}_{55}\right)=8.75$. We replace these values for their corresponding $a_{i j}$ in the convenient assignment problems in the linear programming problem. We solve it by Hungarian method to get the following optimal solution is

$\mathrm{x}{ }_{14}=\mathrm{x} *_{25}=\mathrm{x} *_{32}=\mathrm{x} *_{41}=\mathrm{x} *_{53}=1$

$\mathrm{x} *_{11}=\mathrm{x}{ }_{12}=\mathrm{x}{ }_{13}=\mathrm{x}{ }_{15}=\mathrm{x} *_{21}=\mathrm{x} *_{22}=\mathrm{x}{ }_{23}=\mathrm{x}{ }_{24}=\mathrm{x} *_{31}=\mathrm{x}{ }_{33}=\mathrm{x}{ }_{3}$ ${ }_{4}=\mathrm{x}{ }_{35}=\mathrm{x} *{ }_{42}=\mathrm{x}{ }_{43}=\mathrm{x} *{ }_{44}=\mathrm{x} *_{45}=\mathrm{x} *_{51}=\mathrm{x} *_{52}=\mathrm{x} *_{54}=\mathrm{x} *_{55}=0$ with optimal objective value $\mathrm{R}\left(\check{\mathrm{z}}^{*}\right)=31.25$ which represents a optimal total cost. In other words the optimal assignment is
$\mathrm{A} \rightarrow 4, \mathrm{~B} \rightarrow 5, \mathrm{C} \rightarrow 2, \mathrm{D} \rightarrow 1, \mathrm{E} \rightarrow 3$

The fuzzy optimal total cost is

$\tilde{\mathrm{a}}_{14}+\tilde{\mathrm{a}}_{25}+\tilde{\mathrm{a}}_{32}+\tilde{\mathrm{a}}_{41}+\tilde{\mathrm{a}}_{53}=\mathrm{R}(3,4,6,9)+\mathrm{R}(2,3,5,7)+$

$\mathrm{R}(6,7,9,10)+\mathrm{R}(4,5,7,9) \quad+\mathrm{R}(2,3,10,14) \quad=$

$\mathrm{R}(17,22,37,49)$.

Also we find that $\mathrm{R}\left(\check{\mathrm{Z}}^{*}\right)=31.25$.

Example - 3 Let us consider a Fuzzy Assignment Problem with rows representing 4 persons A,B,C,D, and columns representing the 4 jobs Job1, Job2, Job3, Job4, The cost matrix $\left[\tilde{\mathrm{a}}_{\mathrm{ij}}\right]$ is given whose elements are Triangular or Trapezoidal fuzzy numbers. The problem is to find the optimal assignment so that the total cost of job assignment becomes minimum.

$\left[\tilde{\mathrm{a}}_{\mathrm{ij}}\right]=\left(\begin{array}{cccc}(4,5,6,10) & (3,5,7) & (5,7,9,10) & (2,5,7,9) \\ (4,7,9) & (5,7,9,10) & (4,5,9) & (7,8,10) \\ (5,7,10,11) & (2,5,7) & (7,9,12,13) & (2,3,4) \\ (2,5,7,9) & (3,7,9) & (4,5,7) & (7,9,10,12)\end{array}\right)$

Solution: In Conformation to model (2) the fuzzy assignment problem can be formulated in the following mathematical programming for

$\operatorname{Min}\left\{R(4,5,6,10) x_{11}+R(3,5,7) x_{12}+R(5,7,9,10) x_{13}+R(2,5,7,9\right.$

) $\mathrm{x}_{14}+\mathrm{R}(4,7,9) \mathrm{x}_{21}+\mathrm{R}(5,7,9,10) \mathrm{x}_{22}+$

$\mathrm{R}(4,5,9) \mathrm{x}_{23}+\mathrm{R}(7,8,10) \mathrm{x}_{24}+\mathrm{R}(5,7,10,11) \mathrm{x}_{31}+\mathrm{R}(2,5,7) \mathrm{x}_{32}+\mathrm{R}($

$7,9,12,13) \mathrm{x}_{33}+\mathrm{R}(2,3,4) \mathrm{x}_{34}+$

$\left.\mathrm{R}(2,5,7,9) \mathrm{x}_{41}+\mathrm{R}(3,7,9) \mathrm{x}_{42}+\mathrm{R}(4,5,7) \mathrm{x}_{43}+\mathrm{R}(7,9,10,12) \mathrm{x}_{44}\right\}$

Subject to

$\mathrm{x}_{11}+\mathrm{x}_{12}+\mathrm{x}_{13}+\mathrm{x}_{14}=1 \quad \mathrm{x}_{11}+\mathrm{x}_{21}+\mathrm{x}_{31}+\mathrm{x}_{41}=1$ 
$\mathrm{x}_{21}+\mathrm{X}_{22}+\mathrm{x}_{23}+\mathrm{x}_{24}=1 \quad \mathrm{x}_{12}+\mathrm{x}_{22}+\mathrm{x}_{32}+\mathrm{x}_{42}=1$

$\mathrm{X}_{31}+\mathrm{X}_{32}+\mathrm{X}_{33}+\mathrm{X}_{34}=1 \quad \mathrm{x}_{13}+\mathrm{x}_{23}+\mathrm{X}_{33}+\mathrm{x}_{43}=1$

$\mathrm{x}_{41}+\mathrm{x}_{42}+\mathrm{x}_{43}+\mathrm{x}_{44}=1 \quad \mathrm{x}_{14}+\mathrm{x}_{24}+\mathrm{x}_{34}+\mathrm{x}_{44}=1 \quad \mathrm{x}_{\mathrm{ij}} \in[0,1]$

Now we calculate $\mathrm{R}(4,5,6,10)$ by applying Robust's ranking method. The membership function of the trapezoidal fuzzy number $(4,5,6,10)$ is

$$
\mu(x)=\left\{\begin{array}{cc}
(x-4) / 1, & 4 \leq x \leq 5 \\
1, & 5 \leq x \leq 6 \\
(10-x) / 4, & 6 \leq x \leq 10 \\
0, & \text { otherwise }
\end{array}\right.
$$

The $\alpha$-cut of the fuzzy number $(4,5,6,10)$ is $\left(a_{\alpha}{ }^{\mathrm{L}}, \mathrm{a}_{\alpha}{ }^{\mathrm{U}}\right)=$ $(\alpha+4,10-4 \alpha)$ for which

$$
\begin{aligned}
\mathrm{R}\left(\tilde{\mathrm{a}}_{\mathrm{ij}}\right)=\mathrm{R}(4,5,6,10) & =\int_{0}^{1} 0.5\left(\mathrm{a}_{\alpha}{ }^{\mathrm{L}}, \mathrm{a}_{\alpha}{ }^{\mathrm{U}}\right) \mathrm{d} \alpha \\
& =\int_{0}^{1} 0.5(14-3 \alpha) \mathrm{d} \alpha=6.25 .
\end{aligned}
$$

Proceeding similarly, the Robust's Ranking Indices for the fuzzy costs $\tilde{\mathrm{a}}_{\mathrm{ij}}$ are calculated as:

$\mathrm{R}\left(\mathrm{a}_{12}\right)=5, \mathrm{R}\left(\mathrm{a}_{13}\right)=6.75, \mathrm{R}\left(\mathrm{a}_{14}\right)=5.75, \mathrm{R}\left(\mathrm{a}_{21}\right)=6.75$, $\mathrm{R}\left(\mathrm{a}_{22}\right)=7.75, \mathrm{R}\left(\mathrm{a}_{23}\right)=5.75, \mathrm{R}\left(\mathrm{a}_{24}\right)=8.25, \mathrm{R}\left(\mathrm{a}_{31}\right)=7.75$, $\mathrm{R}\left(\mathrm{a}_{32}\right)=4.75, \mathrm{R}\left(\mathrm{a}_{33}\right)=10.25, \mathrm{R}\left(\mathrm{a}_{34}\right)=3, \mathrm{R}\left(\mathrm{a}_{41}\right)=5.75$, $\mathrm{R}\left(\mathrm{a}_{42}\right)=6.5, \mathrm{R}\left(\mathrm{a}_{43}\right)=5.25, \mathrm{R}\left(\mathrm{a}_{44}\right)=9.5$. We replace these values for their corresponding $\mathrm{a}_{\mathrm{ij}}$ in the convenient assignment problems in the linear programming problem. We solve it by Hungarian method to get the following optimal solution is $\mathrm{x}_{12}=\mathrm{x}_{23}=\mathrm{x}_{34}{ }_{34}=\mathrm{x}_{41}=1$

$\mathrm{x} *_{11}=\mathrm{x} *_{13}=\mathrm{x} *_{14}=\mathrm{x} *_{21}=\mathrm{x} *_{22}=\mathrm{x} *_{24}=\mathrm{x} *_{31}=\mathrm{x}{ }_{32}=\mathrm{x} *_{33}=$ $\mathrm{X}{ }_{42}=\mathrm{X} *{ }_{43}=\mathrm{X} *{ }_{44}=0$ with optimal objective value $\mathrm{R}\left(\check{\mathrm{Z}}^{*}\right)=$ 19.5 which represents a optimal total cost. In other words the optimal assignment is

$\mathrm{A} \rightarrow 2, \mathrm{~B} \rightarrow 3, \mathrm{C} \rightarrow 4, \mathrm{D} \rightarrow 1 \mathrm{R}\left(\check{\mathrm{z}}^{*}\right)=19.5$

The fuzzy optimal total cost is

$\tilde{\mathrm{a}}_{12}+\tilde{\mathrm{a}}_{23}+\tilde{\mathrm{a}}_{34}+\tilde{\mathrm{a}}_{41}=\mathrm{R}(3,5,7)+\mathrm{R}(4,5,9)+\mathrm{R}$ $(2,3,4)+\mathrm{R}(2,5,7,9)$

$=\mathrm{R}(3,5,5,7)+\mathrm{R}(4,5,5,9)+$

$\mathrm{R}(2,3,3,4)+\mathrm{R}(2,5,7,9)$

$=\mathrm{R}(11,18,20,29)$

Also we find that $\mathrm{R}\left(\check{\mathrm{Z}}^{*}\right)=19.5$.

In the above examples it has been shown that the total optimal cost obtained by our methods remains as that obtained by defuzzifying the total fuzzy optimal cost by applying the Robust's ranking method [10].

\section{Conclusions}

In this paper, the assignment costs are considered as imprecise numbers described by fuzzy numbers which are more realistic and general in nature. Moreover, the fuzzy assignment problem has been transformed into crisp assignment problem using Robust's ranking indices [10]. Numerical examples show that by this method we can have the optimal assignment as well as the crisp and fuzzy optimal total cost. By using Robust's [10] ranking method we have shown that the total cost obtained is optimal. Moreover, one can conclude that the solution of fuzzy problems can be obtained by Robust's ranking method effectively. This technique can also be used in solving 
other types of problems like, project schedules, transportation problems and network flow problems.

Acknowledgement: The authors are highly thankful to the referees for their valuable comments and suggestions for improving the paper. This research work was partially supported by J.J EDUCATIONAL HEALTH AND CHARITABLE TRUST, TIRUCHIRAPPALLI-09

\section{References}

[1] C.B Chen and C.M.Klein, " A Simple approach to ranking a group of aggregated fuzzy utilities," IEEE Trans.Syst., Man, Cybern.B, vol.SMC-27, PP. 26-35, 1997.

[2]. Chi-Jen Lin, Ue-Pyng Wen, A labeling algorithm for the fuzzy assignment Problem, Fuzzy Sets and Systems 142 (2004) 373-391.

[3] D.Dubois, P. Fortemps, Computing improved optimal solutions to max-min flexible constraint satisfactions

[4] F.Choobinesh and H.Li, " An index for ordering fuzzy numbers," Fuzzy sets ans Systems, vol 54, pp.287-294, 1993.

[5] M.OL h EL igearaigh, A fuzzy transportation algorithm,Fuzzy sets and Systems 8 (1982) 235-243.

[6] M.Sakawa, I.Nishizaki, Y.Uemura, Interactive fuzzy programming for two level linear and linear fractional production and assignment problems: a case study, European J.Oer.Res.135(2001) 142-157.

[7] M.S.Chen, On a fuzzy assignment problem, Tamkang J. , Fuzzy Sets and Systems 98(1998) 291-29822 (1985) 407411.
[8] M.Tada,H.Ishii, An integer fuzzy transportation problem, Comput.Math.Appl.31(1996) 71-87.

[9] P.Fortemps and M.Roubens, " Ranking and defuzzification methods based area compensation” Fuzzy Sets and Systems, vol.82, pp 319-330, 1996.

[10] R.R.Yager, “ A procedure for ordering fuzzy subsets of the unit interval, Information Sciences, 24,(1981), 143161.

[11]S.Chanas,D.Kuchta, A concept of the optimal solution of the transportation problem with fuzzy cost coefficients, Fuzzy Sets and Systems 82(1996) 299-305.

[12] S.Chanas, D.Kuchta, Fuzzy integer transportation problem problems, European J.Operations Research, 118(1999) 95-126.

[13] S.Chanas, W.Kolodziejczyk, A. Machaj, A fuzzy approach to the transportation problem, Fuzzy Sets and Systems 13 (1984) 211-221.

[14] S.H.Chen, “ Ranking fuzzy numbers with maximizing set and minimizing set", Fuzzy Sets and Systems, 17(1985) 113-129.

[15] X.Wang, Fuzzy optimal assignment problem, Fuzzy Math.3(1987) 101-108.

[16] Zadeh L.A, Fuzzy sets, Information and control 8 (1965) 338-353. 